\title{
In this issue of Occupational Medicine
}

The novel coronavirus outbreak in Wuhan city (Hubei Province central China), now named COVID-19 presents significant public health challenges to health authorities not only in china but across several countries in Southeast Asia and beyond. Koh [20-CA-006] provides a succinct description of coronaviruses are and outlines the six species known to be associated with illnesses in humans. The article traces the origins of these viruses, reports number of known deaths associated with them and case fatality rates. Occupations associated the virus outbreak, and groups at high risk of contracting the infection such as healthcare workers are described. Social stigmatisation associated with COVID-19 is explored and suggested measures to contain the infection detailed.

The future of the NHS is discussed in an insightful article by Goddard's [20-CA-005]. The article examines amongst other issues recruitment challenges of the NHS. Goddard points to an estimated 100,000 vacancies within the NHS, with hospital medicine particularly struggling to recruit because of lack of trainees. In occupational medicine like other specialties, the recruitment challenges remain stark with an increasing number of clinicians working part-time and significant numbers due to retire in the coming years. Suggested solutions include doubling medical school intakes to meet the increasing demand and current losses from the NHS, rapid development of advanced clinical practitioners, the introduction of physician associates and increasing three key determining factors in a individual's occupational satisfaction - autonomy, mastery and relatedness which are reiterated in the recent GMC report 'Caring for doctors Caring for patients'.

The agricultural sector and associated industries represent important segments of many developing and developed economies. Globally, it is estimated that about two million tons of pesticides are used annually in these industries. Notwithstanding the overall positive benefits that the sector brings to society, results of epidemiological studies have suggested that associations exist between occupational pesticide exposure and human ill health. In their systematic review and metanalysis, Ratanachina et al., [OM-19-OP-104.R2] report evidence suggesting that occupational exposure to cholinesterase 
inhibiting pesticides reduced $\mathrm{FEV}_{1} / \mathrm{FVC}$, although no evidence was found to suggest that paraquat exposure affected lung function. Their review also reported high heterogeneity between studies.

Similarly, Perić and Đurđević [OM-18-CR-013.R2] report on a case of a nasal polyp with epithelial dysplasia in a worker employed in the metalworking industry. The worker was occupationally exposed to heavy metals (nickel and copper salt dust) and presented with impaired nasal breathing and mild right-sided epistaxis. He had been exposed to copper and nickel salt dust for six years. This interesting case report discussed the role of nickel and copper salt dusts within the work environment. They suggest that epithelial dysplasia may occasionally be noted in inflammatory nasal polyps, especially in workers exposed to heavy metals.

Work-related musculoskeletal disorder (WRMD) remains a significant problem in many healthcare workers. While the majority of conditions are preventable, there is growing concern about the prevalence of WRMD in surgeons. Grant et al's Australian study [OM-19-OP-056.R5] estimated prevalence in surgeons and identified risk factors for developing work-related neck, shoulder and upper back pain. They reported high prevalence of WRMDs among Australian surgeons. They also found female gender, younger age and fewer years of working were statistically significant risk factors for higher prevalence of WRMDs in surgeons. They suggest the need for further research to validate evidence-based applied ergonomics and physical conditioning programmes to prevent WRMDs in surgeons. They also suggest the incorporation of education on surgical ergonomics as part of formal teaching for surgical trainees.

On a similar theme Lawson [OM-19-CA-031], provides a cogent discussion on working with handheld vibrating tools and Carpal Tunnel Syndrome (CTS). Lawson [OM-19-CA-031] acknowledges the presence of occupational and non-occupational risk factors of CTS and highlights the importance of researchers distinguishing between ergonomic risks from vibration risks in epidemiological studies. Lawson's discussion emphasizes the paucity of guidance for occupational physicians regarding cases of CTS which need reporting as part of prescribed statutory and reportable occupational disease 
requirements in the UK. The article also describes challenges in applying criteria suggested by the Workplace Health Expert Committee (an independent and impartial advisory committee to the Health and Safety Executive) when considering evidence on risks to health in the workplace.

López-Bueno et al.'s study [OM-19-OP-089.R1] sheds light on the less well understood area of how physical activity influences sickness absence among University workers in Europe. The study investigated associations between physical activity and sickness absence in Spanish University workers. It reported that after adjusting for factors including age, sex, job function, chronic conditions, sedentarism and smoking, each weekly hour of physical activity reduced sickness absence by -1.2 days per year. They conclude that implementation of physical activity promotion strategies may lead to reduction in sickness absence among University employees.

Finally, SOM is planning an "art and occupation" book. Do contact them for more details and look out for the 2020 SOM occupational health awards and a new free "find an occupational health provider" service to complement its find an occupational health professional service.

Gordon Jackson-Koku 


\section{References}

1. Koh D. COVID-19. Occup Med (Lond) 2020; 70: XXX-XXX

2. Goddard A. Utopia or dystopia: What does the future hold for the NHS? Occup Med (Lond) 2020; 70: XXX-XXX

3. Ratanachina J, De Matteis S, Cullinan P, Burney P. Pesticide exposure and lung function: a systematic review and meta-analysis. Occup Med (Lond) 2020; 70: XXX-XXX

4. Peric A, Vukomanovic Djurdjevic B. Nasal polyp epithelial atypia and exposure to nickel and copper. Occup Med (Lond) 2020; 70: XXX-XXX

5. Grant K, Vo T, Tiong L. The painful truth: Work-Related Musculoskeletal Disorders in Australian Surgeons. Occup Med (Lond) 2020; 70: XXX-XXX

6. Lawson I. Is Carpal Tunnel Syndrome caused by work with vibrating tools? Occup Med (Lond) 2020; 70: XXX-XXX

7. López-Bueno R, Smith L, Andersen L L, López Sánchez G F, Casajús, J A. Physical activity and sickness absenteeism in university workers. Occup Med (Lond) 2020; 70: XXX-XXX 